\title{
LITERATURA, TEMPO E VERDADE: O FAZER HAGIOGRÁFICO NA LEGENDA ÁUREA ${ }^{1}$
}

\author{
Literature, time and truth: \\ The hagiographic in the Golden Legend
}

Igor S. Teixeira*

\begin{abstract}
RESUMO
O objetivo deste texto é analisar características dos relatos sobre vidas de santos, as hagiografias. A partir da Legenda Áurea, uma compilação hagiográfica atribuída ao dominicano Jacopo de Varazze (†1298), realizamos um exercício a respeito da compreensão e a escrita sobre o tempo na perspectiva cristã. Utilizamos como base conceitual a noção de regime de historicidade, de François Hartog, e concluímos que os relatos sobre santos são importantes elementos para o entendimento do tempo na Idade Média.
\end{abstract}

Palavras-chave: hagiografia; Legenda Áurea; século XIII.

\begin{abstract}
The aim of this paper is to analyze the characteristics of narratives about the lives of saints, the hagiographies. Based on the Golden Legend, a hagiographic compilation attributed to Jacopo de Dominican Savona ( $\uparrow 1298)$, we conducted an exercise over the understanding and the writing about the time in the Christian perspective. As conceptual base, we used the notion of historicity regime, François Hartog, and we have concluded that narratives of saints are important elements for the understanding of time in the Middle Age.
\end{abstract}

Keywords: Hagiography; Golden Legend; $13^{\text {th }}$ century.

* Doutor em História (UFRGS/2011), Professor do Depto. e do PPG em História da UFRGS.

1 Reflexões que integram o projeto de pesquisa "Os Tempos da Santidade: processos de canonização e relatos hagiográficos dos santos mendicantes (séculos XIII e XIV)”, financiado pela Fundação de Amparo à Pesquisa do Rio Grande do Sul (FAPERGS), edital ARD/2012. 


\title{
Introdução
}

\author{
"À la extrémité de l'historiographie, comme sa tentation et \\ sa trahison, il existe un autre discours. On peut le caractériser \\ de quelques traits qui ont seulement pour but ici de le situer \\ dans un voisinage, comme le corpus d'une différence \\ [...] L'hagiographie est un genre littéraire..."
}

(Michel de Certeau. L'écriture de l'histoire)

\begin{abstract}
A mensagem deste trecho revela um dos principais dilemas enfrentados pelos historiadores quando se trata do conceito de história, quais suas características e o que o distingue da literatura. A operação historiográfica consiste numa complexa articulação de conceitos, fontes e texto, que busca dar conta do passado, ou, como diria Marc Bloch, dos homens no tempo. Ao afirmar que a hagiografia é um gênero literário e a traição da historiografia, Michel de Certeau estabeleceu uma linha entre história e literatura. ${ }^{2}$ Em que consiste essa diferença? Está no regime de verdade? Por que a hagiografia é a traição da historiografia? Quais instrumentos de análise auxiliam tanto na definição das fronteiras entre hagiografia e historiografia? Pretendemos, com este texto, fornecer elementos para tentar responder a essas questões.

Acreditamos que a utilização dos relatos de vidas de santos hagiografias - como fonte permite discutir alguns aspectos relacionados à operação historiográfica e a relação entre história e literatura durante a Idade Média, especificamente, na segunda metade do século XIII. Para isso, buscamos como recurso metodológico os regimes de historicidade, de François Hartog, e suas considerações sobre relatos de viagem e alteridade. A fonte aqui analisada é a Legenda Áurea ${ }^{3}$, que foi a compilação hagiográfica mais lida (e ouvida) no Ocidente Cristão a partir do final do século XIII. A partir de suas características narrativas, do encadeamento dos textos e de uma possibilidade interpretativa de sua mensagem, é possível analisar
\end{abstract}

2 CERTEAU, M. de. [1975]. L'écriture de l'histoire. Paris: Gallimard, 2002. p. 316.

3 Neste texto utilizamos diferentes publicações da Legenda Áurea, como as traduções brasileira e francesa (2003 e 2004, respectivamente) e uma edição do texto em latim, em CD-ROM. As citações serão feitas em português, indicando o capítulo (em itálico) e as páginas correspondentes à tradução brasileira. 
a relação entre passado, presente e futuro na compreensão do tempo e sua relação com a história.

Entendido como a forma de articulação dos tempos (passado, presente e futuro) para a definição da ordem dos mesmos no texto, o regime de historicidade, segundo François Hartog, funciona como uma ferramenta de análise importante para a compreensão de uma época ou das formas de entendimento desta época sobre si mesma. ${ }^{4}$ Este autor sistematizou dois regimes de historicidade: o da história-retórica e o da história-Geschichte. $\mathrm{O}$ primeiro está baseado nas noções do mundo Antigo sobre o caráter exemplar do passado, em que havia a distinção entre o que se passou e a exposição do acontecimento. O segundo, baseado na ideia da história como conhecimento de si mesma, iniciado na Alemanha a partir da segunda metade do século XVIII, não mais se estruturava naquela separação e também desfez a ideia de história como lição. ${ }^{5}$ Hartog indicou a existência de um regime de historicidade cristão paralelo a esses regimes, porém, o historiador francês não aprofundou suas análises sobre a questão. Pela definição, o regime de historicidade cristão seria uma forma específica de compreender e narrar os tempos, os acontecimentos e de conceber a relação entre os mesmos considerando a história/vida/trajetória bíblica de Cristo?

Partindo de uma resposta afirmativa a esta questão, acreditamos que na Legenda Áurea há uma interessante proposta sobre os usos do tempo, ou sobre um possível regime de historicidade cristão. Isto porque se trata de um tipo de documento eminentemente religioso, edificante, escrito para fornecer elementos para a elaboração de sermões e promover o culto aos santos. ${ }^{6} \mathrm{O}$ que implica considerar que é um tipo de texto construído para ser inserido numa situação de alocução em que o leitor/ouvinte é convidado a formar juízo sobre aquilo que escreveu/falou o autor/pregador. Além disso, a valorização da tradição e o recurso às autoridades do passado reforçavam a ideia de exemplaridade do que passou. O passado tinha um potencial de fornecer no presente e, principalmente, no futuro, exemplos.

4 HARTOG, F. Temps du monde, histoire, écriture de l'histoire. Conferência apresentada no PANTHEON-IFCH/UFRGS em setembro de 2005. (mimeo) 10 páginas. A obra específica do autor sobre o tema é HARTOG, F. Régimes d'historicité: présentisme et expériences du temps. Paris: Seuil, 2003.

5 HARTOG, F. A arte da narrativa histórica. In: BOUTIER, Jean; JULIA, Dominique (Orgs.). Passados recompostos: campos e canteiros da história. Rio de Janeiro: UFRJ/FGV, 1998. p. 193-202.

6 DELEHAYE, H. Les Légendes Hagiographiques. Bruxelas: Société des Bollandistes, 1927. p. 2. 
O Ocidente Cristão do final do século XIII era um ambiente de conflitos culturais. A Igreja tentava expandir sua ação controladora sobre os fiéis e as ordens mendicantes surgiam como importantes meios de evangelização e consolidação de domínios. Para isso, a Igreja se transformou, modificou rituais ao mesmo tempo em que combatia os movimentos heréticos, assimilou elementos da cultura laica, etc. Um dos conceitos que norteiam o entendimento sobre esse tempo é o de cultura folclórica. Segundo Jean-Claude Schmitt, não se pode atribuir ao folclore características limitadas a apenas um grupo social. ${ }^{7}$ Este conceito permite analisar uma fonte como a Legenda Áurea - que foi escrita por um homem da igreja, Jacopo de Varazze, que dominava o latim, conhecia a tradição filosófica do cristianismo e foi formado nos studia. Jacopo incorporou elementos não oficiais em sua narrativa, ou seja, trouxe, para o mundo da escrita, elementos da oralidade laica e produziu uma compilação repleta de sincretismos - sem colocar barreiras estanques entre a circulação de saberes, as formulações canônicas e a divulgação litúrgica.

No âmbito da construção da narrativa hagiográfica, Jacopo utilizou metáforas e analogias não somente como instrumentos didáticos, mas como expressões de um imaginário medieval baseado numa espécie de pensamento analógico. Ou seja, a forma encontrada para se conhecer o incognoscível a partir da transferência de características do que se conhecia, fazendo comparações, aproximações e inversões. ${ }^{8}$

\section{Hagiografia e História}

Estreitando a relação dos relatos de vidas de santos com uma espécie de narrativa histórica, retornamos à oposição estabelecida no texto de Michel de Certeau. Esta oposição entre hagiografia e historiografia foi formulada pelo autor na medida em que ambas produzem sistemas ou re-

7 SCHMITT, J-C. Le corps, les rites, les rêves et le temps: Essais d'anthropologie médiévale. Paris: Gallimard, 2001. p. 134.

8 FRANCO JÚNIOR, H. Modelo e imagem: o pensamento analógico medieval. In: ENCONTRO INTERNACIONAL DE ESTUDOS MEDIEVAIS DA ABREM, 4., 2003. Anais... Ângela V. Leão e Vanda O. Bittencourt (Orgs.). Belo Horizonte, MG: PUC-Minas, 2003. p. 39-58. 
gimes de verdades diferentes. A historiografia, por estar situada na tensão entre a realidade implicada pela operação científica e a realidade enquanto experiência do vivido, é produto dos procedimentos adotados pelo historiador: desde o inventário dos documentos às interpretações possíveis das séries documentais montadas. ${ }^{9}$ A hagiografia transmite, por sua vez, um outro regime de verdade: a verdade do sagrado, a edificação inspirada pelo culto aos santos. Segundo Certeau, o documento hagiográfico não se refere ao que se passou, e, sim, ao que é exemplar. ${ }^{10}$

Essas reflexões de Michel de Certeau, na verdade, estão baseadas num dos estudos mais clássicos sobre a literatura hagiográfica, a saber, a obra de Hippolyte Delehaye, Les Légendes Hagiographiques, de $1905 .{ }^{11}$ Nas primeiras páginas de sua obra, este estudioso das vidas de santos estabeleceu alguns critérios para diferenciar não somente a história da hagiografia, como também as características inerentes às literaturas que não necessariamente estão relacionadas com a realidade, a saber, a fábula, o mito, o conto, a legenda e o romance. Para Delehaye, essas narrativas não estão sujeitas às severas leis da história e suas especificidades permitem identificar melhor as características da hagiografia.

Essas narrativas, para Delehaye, se dividem em dois grupos: as que se apresentam como o produto espontâneo ou impessoal do gênio popular e as que estão relacionadas às criações artificiais. Sobre o mito, o autor considerou que a palavra é geralmente atribuída a tudo que não tem existência real. Da mesma forma, mítico corresponderia a todo herói que viveu somente na imaginação do poeta. No entanto, Delehaye afirmou que esses não são os sentidos dessas palavras. Segundo o texto, "Le mythe implique essentiellement la personnification d'une force ou d'une idée abstraite, ou, si l'on aime mieux, le mythe n'est autre chose que l'explication des phénomènes de la nature à l'usage des peuples enfants". Sobre o conto, Delehaye afirmou se tratar de uma história inventada. Dentre suas variações estão os contos morais, os quais não estão ligados a um povo específico, e, sim, pertencem à humanidade.

Por fim, e ao contrário, a legenda tem necessariamente uma ligação histórica ou topográfica: "Elle rapporte à un personnage réel des faits

9 CERTEAU, Michel de. L'écriture de l'histoire. Paris: Gallimard, 2002. p. 57.

10 Ibidem, p. 317.

11 DELEHAYE, H. Les Légendes Hagiographiques... Op. cit. 
imaginaires; elle met en scène, dans un droit determiné, des histoires de fantaisie". Neste sentido, a legenda é, por oposição ao mito e ao conto, uma narrativa que supõe um fato histórico, que é o sujeito ou o pretexto. Segundo Delehaye, este é o primeiro pressuposto desse gênero. O segundo elemento é que o fato histórico é ornado ou desfigurado pela imaginação popular. A combinação desses termos, portanto, faz com que o texto se encontre do lado da realidade ou da ficção. Desta forma, "un même récit pourra être classé dans l'histoire ou dans la légende". Delehaye afirmou, por fim, que, como é o elemento fictício que determina a categoria das narrativas legendárias, é por ele que se aplica à hagiografia tal termo e que "le nom de légende s'appliquera toujours à un récit ou à un trait non conforme à l'histoire". ${ }^{2}$

Algumas observações devem ser feitas acerca das considerações de Hippolyte Delehaye: a primeira delas é que se trata de um autor bolandista; a segunda remete ao tempo de escrita da obra em questão. Essas duas ressalvas são importantes na medida em que os bolandistas foram os grandes responsáveis, a partir do século XVII, pela compilação de vidas de santo - Acta Sanctorum - e também pela cunhagem do conceito "hagiografia". Sobre o tempo de composição da obra de Delehaye, as formas de se entender as relações entre mito e história estão permeadas também pelas ideias da história como ciência e do mito enquanto forma de expressão e entendimento primitivo - não sistemático - do mundo. A história como ciência, no século XIX, também chamada de positivista, tinha um compromisso com a crítica documental, a objetividade da verdade, bem como com a ênfase nas documentações oficiais e na entronização dos grandes fatos e personagens do passado. Acerca da relação história e mito é importante ressaltar que este tema ganhou debates no âmbito dos conceitos nas ciências humanas com as classificações de erudito, popular, elite, massa. Tanto é que Delehaye defendeu que a história é ornada ou deformada pela imaginação popular. Aparato conceitual hoje superado. Atualmente e como afirmado anteriormente, trabalha-se aqui com a ideia de cultura folclórica. Afinal, se a reflexão daquele autor fosse apropriada, como explicar um homem da igreja, um erudito, construindo um texto permeado constantemente por elementos culturais dos "peuples enfants"?

Discurso produtor de uma mensagem exemplar, ou legendária (entendido aqui como o que deve ser lido sobre), eis o que Delehaye pen-

12 Ibidem. Essas reflexões estão entre as páginas 4-11 desta obra. 
sou sobre a hagiografia no final do século XIX, início do século XX. A história magistra vitae - desde aquela pretendida por Cícero - tem, ao que se percebe, um grau de parentesco com a literatura notadamente cristã da Idade Média. Isto porque há uma coincidência entre a crença na produção de uma verdade sobre o que se passou e, ao mesmo tempo, a ideia de que o que se passou é exemplar. Na hagiografia, por mais que o objeto central - os valores propagados pelos santos - esteja relacionado com o maravilhoso, há sempre uma ligação com o real.

As semelhanças e referências dos santos com os personagens ilustres - tão valorizados na história dita positivista - podem ser explicadas até mesmo pelo ressurgimento do interesse sobre a matéria hagiográfica no século XIX. Da mesma forma, a redescoberta da Legenda Áurea, que ganhou novas traduções e impulsionou novos estudos durante todo o século XX até o presente. A história do culto aos santos, no cristianismo, é permeada pela relação antitética desta religião monoteísta com possíveis identificações do culto às divindades pagãs, à magia e à idolatria. Segundo Néri Souza, apesar de autores como Agostinho e Jerônimo defenderem o culto aos santos já no início do cristianismo, o combate contra o paganismo e o período de maior censura às práticas devocionais ocorreu nos movimentos da Reforma e da Contrarreforma, no século XVI. ${ }^{13}$ Apesar do controle sobre a santidade ter se intensificado com os processos de canonização na Idade Média Central, as preocupações no final da Idade Média, início do período Moderno, ainda eram latentes. Isto refletiu na produção sobre vidas de santos e na importância da matéria hagiográfica para a Igreja.

Os bolandistas - grupo de pesquisadores reunidos por Jean Bolland (1596-1665) com o objetivo de pesquisar, fazer crítica documental e compilar relatos sobre os santos para cada dia do ano - publicaram os dois primeiros volumes sobre os santos de janeiro em 1643 e em 1709 chegaram ao décimo nono volume. ${ }^{14}$ Segundo René Aigrain, no século XVIII, os bolandistas conheceram seu apogeu e queda em relação ao prestígio e subvenção de pesquisas. O reaparecimento do grupo ocorreria no século XIX, especificamente em 1837, quando da fundação de um novo centro em

13 SOUZA, N. de A. A cristianização dos mortos: a mensagem evangelizadora da Legenda Áurea de Jacopo de Varazze. 1998, 2 v. 517 f. Tese (Doutorado em História) - Faculdade de Filosofia, Letras e Ciências Humanas, Universidade de São Paulo, São Paulo, 1998. p. 10-11.

14 AIGRAIN, R. L'hagiographie: ses sources - ses methodes - son histoire. Poitiers: Bloud \& Gay, 1953. p. 333-334 e passim. A última parte desta obra é sobre a história da hagiografia. 
Bruxelas. O já citado Hippolyte Delehaye ocupou a presidência entre 1912 e 1940, sendo um dos maiores expoentes, para Aigrain, do novo trabalho bolandista. $^{15}$

A ascensão e queda dos primeiros bolandistas no século XVIII e seu ressurgimento no século seguinte, e as concepções sobre a relação da história com a exemplaridade do passado, podem ser consideradas como dois elementos que contribuíram para a retomada dos estudos sobre vidas de santos, não apenas entre aquele grupo. ${ }^{16}$ Por mais que os positivistas trabalhassem com o político, documentado e escrito, a hagiografia tinha um dos elementos centrais para essa concepção de história: os seres de exceção, ou seja, os santos. Neste sentido, eles são os personagens ilustres, portadores da verdade sobre o que aconteceu - por exemplo, com Cristo - e imagens do que deve ser seguido e imitado. ${ }^{17}$

\section{Características do texto hagiográfico}

Michel de Certeau indicou que os relatos hagiográficos, por estarem relacionados às leituras festivas, tinham a função de divertir e, por isso, estavam fora do dogma e da norma. ${ }^{18}$ Ao contrário, acredita-se que os relatos de vidas de santos têm sim relação com um sistema de valores normativo na medida em que a própria relação com o calendário litúrgico denota um tempo ritualizado, instituído e controlado. Assim, a hagiografia funcionaria como um instrumento de propagação de modelos de comportamento. Modelos estes que variaram ao longo dos séculos no período medieval, que chegaram a nós como testemunhos de uma forma específica de registro das crenças e sistemas de valores. Assim como o perfil de santidade variou nos dez séculos chamados de medievais, a escrita sobre esses santos também se

15 Ibidem. p. 342-350.

16 Ibidem. Cf. o último capítulo da obra em questão, intitulado "L'hagiographie moderne en dehors des bollandistes". p. 351-388.

17 VAUCHEZ, A. Saints admirables et saints imitables: Les fonctions de l'hagiographie ont-elles changé aux derniers siècles du Moyen Âge?. In: _. Les fonctions des saints dans le monde occidental (IIIe-XIIIe siècle). Roma: École Française de Rome, 1991. p. 162-172.

18 CERTEAU, M. de. L'écriture de l'histoire... Op. cit., p. 322. 
modificou na medida em que avançaram o poder e a expansão dos domínios da Igreja sobre os indivíduos em geral e sobre as suas relações com o além e o sobrenatural. ${ }^{19}$

Neste caso, fala-se especificamente da custódia progressiva sobre a santidade que, na Baixa Idade Média, passou a ser controlada pelos processos de canonização. Desta forma, para se chegar à especificidade da hagiografia, é preciso tratar dos elementos textuais que permaneceram recursos retóricos, analogias, etc - e dos que se transformaram ou surgiram após a instituição desses processos. É importante ressaltar, desde já, que os processos de canonização e a pretensão de controle sobre a santidade pelo papado não eliminaram a coexistência da santidade oficial com as santidades locais e/ou santos não canonizados.

A hagiografia é um relato sobre vida de santo geralmente escrito para ser inserido num sermão, com o objetivo de transmitir uma lição aos ouvintes. Entre a norma e o dogma, o lazer e a edificação, produz uma visualização dos milagres, do martírio e dos lugares de devoção. ${ }^{20} \mathrm{O}$ clímax do texto está na conversão, que, na Legenda Áurea, se dá muitas vezes diante do martírio. Numa combinação de torturas, resistência, corpos mutilados e, ao mesmo tempo, intocáveis, odores e sangue, o santo se revela como um ser de exceção ${ }^{21}$, caracterizado como intercessor pelos homens junto a Deus. A forma básica do texto é o exemplum. Definido como um "conto breve dado como verídico (= histórico) e destinado a ser inserido num discurso (em geral, um sermão) a fim de convencer um auditório por meio de uma lição salutar" 22 , o exemplum era um recurso oratório da Antiguidade que sofreu modificações até assumir esta forma narrativa na Idade Média central. Ligado ao narrativo, está baseado num tempo sucessivo e persuasivo. Daí sua relação com a memória, a consciência espiritual e moral. É importante ressaltar que desde 1215 a obrigatoriedade da confissão auricular marcou a importância da introspecção e uma "nova educação da memória" no Ocidente Cristão. Um aspecto importante relacionado à sucessão temporal nas hagiografias é a perspectiva da salvação para a vida eterna, que é um tempo infinito:

19 VAUCHEZ, A. O santo. In: LE GOFF, J. (Org.). O homem medieval. Lisboa: Presença, 1989. p. $211-230$.

20 CERTEAU, M. de. L'écriture de l'histoire... Op. cit., p. 316-355.

21 KLEINBERG, A. Histoire des Saintes: leur rôle dans la formation de l'Occident. Paris: Gallimard, 2005. p. 15 e passim.

22 LE GOFF, Jacques. O imaginário medieval. Lisboa: Editorial Estampa, 1994. p. 123. 
A história, narrada na sucessividade do conto e historicamente situada numa realidade temporal em geral próxima, deve conduzir à eternidade - prometida ao ouvinte do exemplum se este souber extrair por si próprio a lição. Mas, num primeiro tempo, o conto exemplar deve provocar no ouvinte um acontecimento decisivo para a sua salvação futura: a sua conversão. O exemplum é um instrumento de conversão e esta conversão deve efetuar-se imediatamente. O pregador chama frequentemente o seu auditório a extrair hodie a lição encerrada no sermão e nos exempla que este contém. O tempo histórico do exemplum tende para um presente de conversão que deverá dar início à futura entrada na eternidade da bem-aventurança. $\mathrm{O}$ exemplum tem, pois, como função enxertar a realidade histórica na aventura escatológica. O tempo do exemplum está sujeito à dialética tempo da história-tempo da salvação... ${ }^{23}$

A tensão temporal nas hagiografias funciona também como um recurso de aproximação do tempo que se conta no tempo em que se conta, pois facilita a inserção das metáforas e, consequentemente, da mensagem evangelizadora pretendida, ou seja, a conversão. Mais ainda, a conversão pela palavra e pelo gesto. O que revela não somente um universo simbólico complexo como um tempo ritualizado, cujo princípio sugere ou um tempo de erro, que deve ser redimido, ou um tempo áureo, que deve ser recuperado. ${ }^{24}$

Mas, principalmente, a hagiografia é um texto que procura retraçar os passos, em vida, do santo, sem pretender ser uma biografia. Um veículo de divulgação e acesso à salvação. O santo é uma vitrine de valores e retidão e é na divulgação desses valores que a hagiografia está centrada.

\section{Jacopo de Varazze e a Legenda Áurea}

A biografia de Jacopo de Varazze é perpassada pela imprecisão de sua data de nascimento. No verbete "Giacomo da Varazze" da Enciclopédia

23 Ibidem, p. 126. Grifos do autor.

24 Ibidem, p. 123. 
Católica a data aproximada é $1230 .{ }^{25} \mathrm{Na}$ tradução brasileira da Legenda Áurea, a data é $1226 .{ }^{26}$ Alain Boureau situa entre 1226 e $1228 .{ }^{27}$ Apesar disso, o dado consensual é o de sua morte, 1298. Jacopo de Varazze (1229-1298) formou-se nos studia dominicanos (ordem religiosa para a qual entrou em 1244); ensinou teologia e pregou em Gênova, Viterbo e em outras cidades da península itálica entre 1252 e 1267 . Entre 1267 e 1277 e de 1281 a 1286, foi Prior Provincial na Lombardia. Em 1292, assumiu o Arcebispado de Gênova - cargo que ocupou até falecer. Além da Legenda Áurea, escreveu Sermones de sanctis e Sermones dominicales (1277-1281), Sermones quadragesimales (1285-1292) e o Liber Marialis (1295). Jacopo escreveu ainda um texto que até hoje é considerado como fonte imprescindível para a história de Gênova: Chronicon Ianuense ou Chronica Civitatis Ianuensis ab origine usque ad annum MCCXCVII (1297). Obras que, segundo Stefania Bertini Guidetti, foram de certo modo ofuscadas pela proeminência da Legenda Áurea, mas que, ao invés de serem vistas como inferiores, são derivadas dela. ${ }^{28}$

Em relação à sua obra aqui analisada, trata-se de um best-seller, segundo Sherry Reams. ${ }^{29}$ Sucesso expresso já na modificação do título: inicialmente concebida como Legenda Sanctorum alias Lombardica hystoria, passou a ser chamada de Legenda Áurea. ${ }^{30}$

Este sucesso também é comprovado pela localização de inúmeros manuscritos em diferentes países da Europa Ocidental, pela quantidade de

25 STICCO, M. Giacomo da Varazze. In: Enciclopedia Cattolica. Tomo VI (GENI-INNA). Firenze: Casa Editrice G.C. Sansoni. Città del Vaticano, 1951. p. 332-333. Cf. também a versão on-line, cujo verbete foi escrito por OTT, M. Beato Jacopo de Vorgagine. The Catholic Enciclopedic, v. 1. Versão impressa 1907, disponibilizada on-line em 1999 no site: <http://www.enciclopediacatolica.com/j/jacopovoragine.htm>, consultado em janeiro de 2013.

26 FRANCO JÚNIOR, H. Apresentação. In: JACOPO DE VARAZZE. Legenda Áurea: vidas de santos. São Paulo: Cia das Letras, 2003. p. 12.

27 BOUREAU, A. Chronologie. In: JACQUES DE VORAGINE. La Légende dorée. Texte traduit, presente et annoté par Alain Boureau, Pascal Collomb, Monique Goullet, Laurence Moulinier et Stéfano Mula. Paris: Gallimard, 2004. (Bibliothèque de la Pléiade). p. LV-LVI.

28 GUIDETTI, S. B. Scritura, Oralità, Memoria: la Legenda Aurea fonte e modello nei Sermones e nella Chronica Civitatis Ianuensis di Iacopo da Varagine. In: FLEITH, B.; MORENZONI, F. (Dirs.). De la Sainteté a l'Hagiographie: Genèse et usage de la Légende Dorée. Genebra: Droz, 2001. p. 123-138.

29 REAMES, S. L. The Legenda Aurea: A Reexamination of Its Paradoxical History. Londres: The University of Wisconsin Press, 1985. A autora analisa como a obra de Jacopo de Varazze foi lida, utilizada, abandonada e recuperada em termos de importância na literatura hagiográfica ocidental.

30 DUNN-LARDEAU, B. Préface. In: (Dir.). Legenda Aurea: sept siècles de diffusion (Actes du Colloque international sur la Legenda Aurea: texte latin et branches vernaculaires; Universitè du Québec, Montreal; 11-12 mai, 1983). Montreal/Paris: Bellarmin/Librairie J. Vrin, 1986. p. 13-16. 
manuscritos com a indicação pecia $^{31}$ e pelo fato de superar o número de edições da Bíblia no século XV. ${ }^{32}$

A profusão de manuscritos gerou, inclusive, a dificuldade de se estabelecer uma edição "original" da obra e inspirou a tese de Giovanni Paolo Maggioni acerca das diversas fases de redação da obra. A pesquisa desse filólogo é um extenso trabalho a partir dos manuscritos mais antigos encontrados nas regiões onde viveu Jacopo de Varazze. ${ }^{33}$ Segundo Maggioni, é possível que Jacopo tenha revisitado e ampliado seu texto até o fim da vida. $\mathrm{O}$ autor trabalhou com dois momentos. O primeiro, entre 1272-1276, quando Jacopo foi Prior Provincial da Lombardia e vivia em Bolonha. ${ }^{34}$ Para este período, Maggioni trabalhou com um conjunto de 30 manuscritos e chamou-os de versão "ampliada" da Legenda. O segundo momento, entre 1292-1299, quando Jacopo foi Arcebispo de Gênova pela segunda vez, cidade onde permaneceu até a morte, em $1298 .{ }^{35}$ Segundo Maggioni, esses dois conjuntos denotam a revisão da obra e podem ser considerados como testemunho privilegiado da vontade do autor. ${ }^{36}$ Além disso, Maggioni considerou que existem várias versões por causa desses momentos

31 Segundo Jacques Verger, o sistema da pecia "consistia em confiar aos livreiros da universidade exemplares oficialmente controlados dos principais livros de estudo; tais exemplares eram feitos de cadernos (pecioe) não ligados, o que permitia serem alocados para inúmeros copistas ao mesmo tempo; estes podiam, então, produzir simultaneamente muitas cópias do mesmo livro.” VERGER, J. Homens e saber na Idade Média. Trad. Carlota Boto. Bauru, SP: EDUSC, 1999. p. 113. A utilização deste recurso era para as obras usadas nas universidades. A localização de manuscritos da Legenda com essa inscrição abre possibilidades para outro tipo de uso da obra. Ainda que ela não tenha sido estudada nas grades curriculares, ela foi lida pelos que frequentavam as cátedras.

32 Cf. FLEITH, B. Le Classement des quelque 1000 manuscrits de la Legenda Aurea latine en vue de l'établissement d'une histoire de la tradition. In: DUNN-LARDEAU, B. (Dir.). Op. cit., p. 19-24 e FLEITH, B. Legenda Aurea: destination, utilisateurs, propagation. L'histoire de la diffusion du légendier au XIIIe et au bébut du XIV siècle. In: GAJANO, S. B. (Cura). Raccolte di vite di santi dal XIII al XVIII seccolo. Fasano di Brindisi: Schena, 1990. p. 41-48. A diversidade de manuscritos da Legenda Áurea atua até hoje como obstáculo para o estabelecimento de um corpus original da obra. A professora Bárbara Fleith, de 1977, quando iniciou um mapeamento dos manuscritos do século XIII ao XV, a 1986, com a defesa de sua tese de doutorado, pesquisou a "história da tradição latina" da Legenda Áurea. Na tese, consta um catálogo de variações do texto e de possibilidades de abordagem dos aspectos culturais e linguísticos relacionados à obra. Cf. FLEITH, B. Studien Zur Überlieferungsgeschichte der Lateinischen Legenda Aurea. Bruxelles: Société des Bollandistes, 1991. (Thèse n² 273).

33 MAGGIONI, G. P. Ricerche sulla composizione e sulla transmissione della "Legenda Aurea". Firenze: SISMEL-Spoleto, 1995. (Biblioteca di Medioevo Latino, 8).

34 O cargo de Prior Provincial exercido por Iacopo iniciou em 1267. Entretanto, segundo Maggioni, a data do primeiro conjunto de manuscritos analisados não pode ser estabelecida antes de 1272 porque nesses manuscritos há referência a uma obra desconhecida até esse ano. Ibidem, p. 10.

35 Ibidem, p. 96.

36 Ibidem, p. 11. 
diferenciados de composição. Isto sugere, ainda, diferentes itinerários de leitura. ${ }^{37}$ As mudanças percebidas por Maggioni estão relacionadas ao número de capítulos, de fontes e o modo de citá-las. Segundo o texto, Jacopo teria adaptado a obra para um universo além do púlpito, abrangendo, por exemplo, um público leitor com certa erudição. ${ }^{38}$

Especificamente sobre a Legenda Áurea, Alain Boureau acrescenta:

Les récits qui la componsent reçoivent une fonction d'édification et proposent une pédagogie du sacré. A la difference d'autres textes hagiographiques, la vulgarization narrative propose plus qu'un modèle de conduite religieuse, mais un véritable corpus de dogmes. ${ }^{39}$

Para este autor, por conta dessas características, a Legenda Áurea é um texto de divulgação, pois foi mais dirigida aos fiéis do que aos clérigos e, por isso, é também singular em relação aos outros relatos e/ou compilações hagiográficas. Por se tratar de um conjunto de textos, as formas para analisar esta fonte podem ser diversas: todo o conjunto, temas, personagens, festas, milagres, pecadores, por referências externas ou internas. Alain Boureau fez, sem dúvida, o estudo mais sistemático sobre esta obra até o momento: conhecedor do universo cultural de Jacopo de Varazze, analisou as fronteiras entre o clerical e as tradições leigas, os recursos de oralidade inseridos nas legendas e as formas de entrelaçamento entre o dogma e a narrativa.

Segundo Alain Boureau, Jacopo preferiu utilizar modelos arcaicos sobre os martírios e os milagres, fazendo-se valer do maravilhoso cristão

37 Idem. "Le Molte Legende Auree: Modificazioni testuali e itnerari narrativi". In: FLEITH, B.; MORENZONI, F. Op. cit., p. 15-40.

38 Ibidem, p. 19-32. Alguns historiadores divergem da tese de Maggioni, como é o caso da pesquisadora brasileira Néri de Almeida Souza. Segundo a autora, "A despeito da importância dastas [sic] proposições, os critérios de datação precisam ser reavaliados. Em primeiro lugar porque a lógica das citações de Jacopo de Varazze nem sempre respeita os eventos importantes de seu tempo, daí a ausência de textos tomados de empréstimo a Tomás de Aquino ou de legendas consagradas à festa de Corpus Christi. Tais lacunas não são suficientes para caracterizar a anterioridade da Legenda Áurea a determinados eventos ou à atuação de certas personagens de destaque, uma vez que seu autor é profundamente tradicionalista em suas opções temáticas. Em segundo lugar, a hipótese das duas versões, desenvolvida por Maggioni, embora bem fundamentada, não se mostra suficiente para a defesa da cronologia que dá respaldo à composição, uma vez que o autor se limita a instrumentalizar, sem reavaliar, a cronologia proposta por P. Devos". Cf. SOUZA, Néri de A. A cristianização dos mortos... Op. cit., p. 54-55, especificamente nota 4.

39 BOUREAU, A. La Légende Dorée: Le systhème narratif de Jacques de Voragine (†1298). Paris: Cerf, 1984. p. 12. 
em muitas de suas facetas, tanto eruditas quanto populares. Ao analisar o sistema narrativo da Legenda Áurea, Boureau procurou entender três paradoxos revelados a partir desta característica: o primeiro é a diferente postura adotada nos escritos sobre a doutrina (comparando com Tomás de Aquino, por exemplo); o segundo está relacionado ao fato de ser uma obra que emana de uma Igreja urbana, produzida nos chamados lugares de saber do século XIII, que, emblematicamente, insere referências não clericais nos relatos, combinando elementos culturais diferentes. $\mathrm{O}$ terceiro paradoxo advém da forma como o próprio texto hagiográfico ou legendário muitas vezes é definido: por ser apresentado em forma de contos ou de mitos, muitas vezes é entendido como um estilo de texto literário fundamentalmente popular.

A esses paradoxos, Boureau respondeu que a produção desse tipo de texto é muito ambígua. Para a Legenda Áurea, por exemplo, não se fala em autoria de Jacopo de Varazze e, sim, tem-se nele a figura daquele que compilou textos, sermões e aspectos de oralidade e os reuniu, ordenando, adaptando e disponibilizando um farto material para consulta, elaboração de sermões e lazer. É de Boureau uma expressão com a qual concordamos: Jacopo muitas vezes realizou uma espécie de "pátina" hagiográfica. ${ }^{40}$

Em princípio, a relação com o calendário litúrgico remete a hagiografia ao uso festivo. Os feitos milagrosos e o imaginário que perpassam o poder, a superioridade dos santos e a relação destes com os fiéis e com os infiéis dão aos relatos de suas vidas aspectos literários, cujo caráter ficcional revela um texto evangelizador.

A manipulação do tempo é uma das principais características de qualquer calendário. No âmbito da literatura, esta manipulação é ainda mais livre, o que não deixa de ser intencional. Com base nos quatro tempos litúrgicos (Renovação, Desvio, Reconciliação e Peregrinação), percebemos que há na Legenda Áurea uma modificação explícita na sequência bíblica: o tempo do Desvio é o da queda de Adão, ou seja, o primeiro "tempo" bíblico; o tempo da Renovação é o tempo da vinda de Cristo, que reaproximou os homens de Deus ao redimir os erros dos primeiros pais. Mas é o tempo da Renovação que abre o texto, não o tempo do Desvio. Qual a razão desta modificação? A resposta é um tanto quanto óbvia, e fornecida pelo próprio Jacopo de Varazze:

40 Idem. La patine hagiographique. Saint Pirerr Martyr dans la Légende Dorée. In: RENARD, E.; TRIGALET, M.; HERMAND, X.; BERTRAND, P. (Éds.). Scribere Sanctorum gesta: Recueil d'études d'hagiographie medieval offert à Guy Phillipart. Turnhout: BREPOLS, 2005. p. 359-366. 
Embora o Desvio tenha precedido a Renovação, a Igreja prefere começar todos os seus ofícios no tempo da Renovação, por dois motivos. O primeiro, para não parecer começar no tempo do erro [...] O segundo, porque com o Advento de Cristo tudo foi renovado. ${ }^{41}$

Aliada a esta questão, temos a utilização de recursos retóricos como as analogias e as metáforas. Recursos utilizados para a aproximação das crenças e mistérios intangíveis à realidade, principalmente, daqueles que ouviam as histórias bíblicas. Ampliando a questão, Hilário Franco Júnior considerou que existia uma visão analógica de mundo e que as comparações extrapolavam o uso como recurso retórico. ${ }^{42}$ Ao analisar três aspectos que envolvem esta questão no Ocidente Medieval - Pecado Original, a pregação litúrgica e as imagens sobre esse pecado -, o autor identificou duas formas gerais de analogias: proporção e atribuição (podendo, ambas, serem diretas, indiretas e invertidas).

A Legenda Áurea apresenta inúmeros casos de analogia por inversão, principalmente quando são feitas referências da missão de Cristo em redimir Adão. ${ }^{43} \mathrm{O}$ significado dessa remissão transmite também a ideia de erradicação do mal. As campanhas para extirpá-lo da cristandade são sempre travadas na Legenda Áurea a partir de um referencial comum: o outro não cristão, principalmente os pagãos e, com mais veemência, os judeus.

Sobre os pagãos, em dois momentos pode-se perceber o combate aos seus costumes e a transformação destes em elementos com significado cristão: no primeiro momento, ao encerrar a legenda sobre $A$ Circuncisão do Senhor, Jacopo afirmou que havia um costume pagão de realizar festas e muitas superstições (os homens se fantasiavam com roupas de mulheres ou com máscaras de peles de animais, trocavam presentes diabólicos, banquetes, etc.) no dia da procissão consagrada à purificação de Cristo. Segundo o texto, os santos tiveram muito trabalho para extirpar esse costume, inclusive entre os cristãos. Citando Santo Agostinho, Jacopo finalizou o texto considerando que não era digno do nome de cristão aquele que participava

41 Prólogo de As Legendas dos santos ou História Lombarda, compiladas pelo genovês Frei Jacopo, da Ordem dos Irmãos Pregadores, p. 42. Grifo nosso.

42 FRANCO JÚNIOR, H. Modelo e imagem: O pensamento analógico medieval... Op. cit., p. 43.

43 O Advento do Senhor, p. 49 e passim 
dessas festas e que o verdadeiro cristão deveria não somente evitar, como repreender, corrigir e castigar tais costumes. ${ }^{44}$

$\mathrm{O}$ segundo momento trata do terceiro nome atribuído à festa da Purificação da Virgem, que é chamada também de Candelária. Segundo o texto, era costume levar à Igreja no dia da festa da purificação uma vela acesa, daí o terceiro nome. A principal razão de se levar esta vela é a seguinte:

Como é difícil abandonar os costumes arraigados, os cristãos recém-convertidos não sabiam o que conservar dos costumes pagãos, levando o papa Sérgio [I, 687-701] a atribuir um sentido melhor à festa. Ele ordenou aos cristãos de todo o mundo que a cada ano, nessa data, celebrassem uma festa em homenagem à Santa Mãe do Senhor, com círios acesos e velas bentas. Desta maneira a solenidade permanecia, mas sua intenção era outra. ${ }^{45}$

A transformação das intenções e a ressignificação dos símbolos, neste caso, nos dão as medidas do esforço de Varazze no combate daquilo que ele chamou de "maus costumes".

Sobre os judeus, as referências são ainda maiores, mais explícitas e mais enfáticas. Maiores quantitativamente em relação aos pagãos (são mais citados), mais explícitas porque muitas vezes o outro (não cristão) combatido por Varazze é referenciado quase sempre como judeu, e mais enfáticas porque tratam de duas figuras simbolicamente mais importantes na devoção da divindade no catolicismo: Cristo e Maria.

Nas legendas sobre Cristo, temos as referências aos judeus, principalmente no que tange à ciência dos acontecimentos e ações que faziam dele o filho de Deus, como na circuncisão: "Cristo quis ser circuncidado para que os judeus não tivessem desculpas. Se não tivesse sido circuncidado, os judeus teriam podido dizer: 'Não o aceitamos porque você não se parece com nossos pais"'. ${ }^{46} \mathrm{Na}$ Paixão, um dos motivos pelos quais Cristo foi entregue à morte, segundo Jacopo, foi a "inveja dos judeus" 47 , pois, quando quiseram se certificar de que atingiriam a alma de Cristo, feriram os três lugares onde se acreditava que ela estava localizada: a coroa de

44 A Circuncisão do Senhor, p. 148.

45 Purificação da Bem-Aventurada Virgem Maria, p. 249.

46 A Circuncisão do Senhor, p. 145.

47 A Paixão do Senhor, p. 329. 
espinhos (alguns achavam que estava na cabeça), as veias das mãos e dos pés abertas (outros achavam que estava no sangue) e o flanco trespassado no peito (outros achavam que era no coração). ${ }^{48}$

Nas legendas sobre Maria, Jacopo faz referência aos judeus no texto sobre a Assunção: quando os apóstolos de Cristo carregavam o féretro da Virgem, os judeus tentaram atacar o cortejo e aqueles que não acreditavam que era ela que estava sendo conduzida pelos apóstolos com o coro dos anjos ficaram cegos. Só recuperaram a visão quando assumiram a crença, não somente na Virgem, como também em seu Filho. ${ }^{49}$ Nesta legenda, percebemos como o autor/compilador se apropriou de textos mais prolixos e os adaptou de modo a ficarem mais simples, reduzindo as explicações dos mistérios e enfatizando a Virgindade, a Pureza e os poderes de Maria. Isto porque, ao final do seu texto, há textos de outros autores e outras compilações sobre o mesmo assunto.

A partir dessas questões, podemos afirmar que o texto hagiográfico expressa um processo de atribuição de identidades: a conversão, a denominação de um "inimigo" e a caracterização do outro. A alteridade hagiográfica não consiste no fato de se falar de uma outra sociedade e, sim, dos outros inseridos na cristandade, como é o caso dos judeus. Este processo de escrita, imaginação e identificação do outro foi analisado por François Hartog na sua obra $O$ espelho de Heródoto. ${ }^{50}$ Entre as considerações do historiador francês sobre as Histórias de Heródoto e as observações explicitadas neste trabalho sobre a Legenda Áurea, é possível fazer uma análise aproximada de alguns elementos característicos de textos que são expressões de identidade e que podem nos fornecer aspectos que compõem o imaginário coletivo sobre o outro, o eu e o nós.

Hartog forneceu um importante modelo de análise para as narrativas de viagem. As operações retóricas para a construção deste tipo de texto remetem a características que também são encontradas no texto hagiográfico. A primeira delas, ou seja, a operação de tradução, configura um elemento aproximativo entre o mundo que se conta e o mundo em que se conta. Geralmente, por inversão, o viajante transforma o que viu e que

48 A Paixão do Senhor, p. 324.

49 A Assunção da Bem-Aventurada Virgem Maria, p. 661-663 e passim.

50 HARTOG, F. O espelho de Heródoto: ensaios sobre a representação do outro. Belo Horizonte: Ed. UFMG, 1999. 
não sabe como chamar no contrário de algo que lhe é próximo ou mais familiar. Esta aproximação de coisas diferentes entre si revela, então, as outras características do relato de viagem: a comparação, a analogia, a classificação e a nomeação. ${ }^{51}$ Estes elementos fazem do relato de viagem um texto descritivo, no qual, segundo o autor, descrever é fazer ver.

Além dessas características, outra semelhança entre as Histórias de Heródoto e as hagiografias é a medida e a importância do maravilhoso. Neste caso, Hartog define que se trata de um recurso retórico de atração e de transcrição possível das diferenças entre o "aqui" e o "além". Outro aspecto advindo desta mensuração na obra de Heródoto é a relação do maravilhoso com o fato de ser "digno de memória". ${ }^{52} \mathrm{E}$, por ser digno de memória, o maravilhoso se revela como expressão de uma coletividade, pois pressupõe que assim o é não somente para o autor do relato, mas também para seu público. Assim, é um elemento que permite supor um conjunto de representações coletivas sobre um tema. É importante ressaltar que se trata de uma inserção progressiva no relato: do menos ao mais admirável, o que faz deste um elemento também de exceção. ${ }^{53}$

A partir dessas considerações, é importante perguntar: como esses elementos se expressam nas hagiografias, em geral, e na Legenda Áurea, em específico? Analisando as transformações ocorridas com os textos que retratam a vida de São Marcelo (bispo de Paris, morto por volta de 436 d.C.), Jacques Le Goff afirmou que "chaque étape du cursus ecclésiastique de Marcel suit un miracle, et la succession de ces miracles est elle aussi qualitative: chacun est supérieur à celui qui l'a précédé". ${ }^{54}$ A sequência dos atos milagrosos do Bispo de Paris está proporcionalmente ligada à sua ascensão nos cargos eclesiásticos. Do primeiro milagre, considerado por Le Goff como um milagre da vida cotidiana e do ascetismo, ao último, a vitória contra o Dragão, São Marcel tem mais que um significado religioso para Paris: o triunfo do santo é, segundo o texto, relatado como um discurso fundador, pois o santo libertou um território de um monstro. E não um monstro

\footnotetext{
51 Ibidem, p. 229-271.

52 Ibidem, p. 246.

53 Ibidem, p. 248.

54 LE GOFF, J. Culture Cléricale et traditions folkloriques dans la civilisation mérovingienne. In: _. Pour un autre Moyen Âge: Temps, travail et culture en Occident (18 essais). Paris: Gallimard, 2001.p. 237.
} 
qualquer. Para Le Goff, os significados medievais do Dragão remetem-no a uma semelhança ou identificação com o Diabo-Serpente. Sendo assim, São Marcel não somente libertou, como extirpou o mal. ${ }^{55}$ Isto faz o relato sobre São Marcel ser não somente exemplar, mas "digno de memória", pois expressa uma identidade de lugar. E uma exceção, pois foi a ação decisiva de um bispo, que depois se tornou santo, que assegurou a libertação da ville.

Foi Michel de Certeau quem afirmou que um relato sobre vida de Santo exerce o mesmo movimento que o relato de viagem, mas que não se trata da descrição de uma outra sociedade. Para este autor, a escrita da vida do santo conduz à visão do lugar. As semelhanças entre o relato de viagem e a hagiografia se dão porque a vida do santo produz uma leitura itinerária:

il prend en charge dans sa première partie le monde 'mauvais' pour conduire sur les traces du saint vers le lieu dit. C'est le côté 'édifiant' de l'hagiographie, soit sous une forme parénétique, soit sur le mode d'un jugement prononcé contre le 'monde' (la première partie est la place privilégiée des combats avec le demon). ${ }^{56}$

Isto porque a hagiografia é uma composição de lugares que se tornaram litúrgicos e, neste itinerário, a vida do santo funciona como expressão de uma coletividade por supor a existência do grupo numa combinação de lugares contrários: o lugar perdido com o lugar atual; ou o lugar a ser reencontrado com o lugar em que as coisas estão se perdendo. Para Michel de Certeau, a hagiografia fala, portanto, de um sentido de lugar num não-lugar. Esta combinação de contrários ou a relativização do lugar revela uma composição particular dos mesmos e que tende a misturar o mundo que se conta no mundo em que se conta. Daí a presença dos elementos de tradução, classificação, comparação e analogias, sempre com o objetivo de passar uma mensagem, no caso da hagiografia, evangelizadora.

A mensagem evangelizadora das hagiografias revela a riqueza de seus conteúdos: como o objetivo é mostrar o que é exemplar, temas como sexualidade, casamento, virgindade, usura, pecado e as relações entre os 
vivos e os mortos são recorrentes. ${ }^{57}$ A Legenda Áurea, por ser uma obra de conjunto, torna-se ainda mais rica, pois as mensagens são endereçadas tanto aos clérigos quanto aos fiéis. No primeiro caso, a Vida de São Bento é exemplar devido à sua recusa aos bens materiais e à fuga para o deserto (neste caso, não necessariamente o deserto como um lugar árido, e, sim, a referência a um lugar inóspito, como, por exemplo, uma gruta de difícil acesso, quase incomunicável) ${ }^{58}$; a vitória sobre as tentações do diabo (personificado numa mulher que tentava seduzi-lo) $)^{59}$; a disciplina exigida dos demais monges enquanto esteve em contato com os homens (batia num monge que não conseguia se concentrar para as preces $)^{60}$, dentre outras questões. No segundo caso, a vida de Santa Juliana, que conta seus problemas com o marido, "quando disse que só teria relações sexuais se ele aceitasse a fé em Cristo". ${ }^{61}$

Estas duas mensagens são exemplares porque, para os clérigos, fornece, no primeiro caso, o exemplo da retidão, do ascetismo e da disciplina; para as mulheres, por exemplo, a segunda legenda mostra os valores da fé cristã e do sexo após o casamento. Considerando esses temas, pode-se perceber uma relação muito próxima do texto com os atos da Igreja nos séculos XII e XIII, principalmente no que tange às práticas sexuais. Assim, a Hagiografia em geral e a Legenda Áurea em específico evidenciam formas de pensamento não somente da Igreja enquanto instituição, mas também são expressões de uma instituição que intenta o controle sobre uma coletividade. Os homens de saber ligados à Igreja entendiam que era preciso cristianizar lugares, crenças e os relatos, assim como faziam/fizeram com o tempo, criando o calendário litúrgico. Antes de tudo, este calendário é uma organização do tempo do sagrado não somente por dividir o ano a partir do ciclo crístico, mas também por determinar os dias para louvar cada santo. Daí a substituição de divindades por santos e a ressignificação de práticas pagãs em práticas cristãs.

57 No Brasil, o estudo mais sistemático sobre a morte na Legenda Áurea é a tese de doutoramento de Néri de Almeida Souza. Este trabalho, apesar de muito bem sistematizado, não se insere nas discussões pretendidas para a problemática em questão.

58 São Bento, p.297-306.

59 Ibidem, p. 297-298.

60 Ibidem, p. 299.

61 Santa Juliana, p. 266. 


\section{Hagiografia e sociedade na segunda metade do século XIII}

Retomando os principais aspectos da hagiografia, temos: gênero literário edificante; passado como exemplaridade e singularidade; baseado na vida de um santo. É importante ressaltar que a construção de uma hagiografia é posterior à vida do personagem. Neste sentido, é, também, a busca por um sentido e por um efeito de verdade, que é obtido a partir do comportamento santo e dos feitos milagrosos, os quais distinguem o mundo que se conta do mundo em que se conta, além, claro, da separação entre aquele sobre o qual se conta e aqueles para os quais se conta. Estas distinções estão relacionadas com a temporalidade expressa no texto hagiográfico: ou se fala de um tempo perdido que deve ser recuperado, ou se fala de um tempo vindouro, que corrigirá o tempo do mundo em que se conta.

No caso da Legenda Áurea, é mais presente a ideia de que tudo foi dado nas origens: primeiro o pecado, depois a remissão. Assim, um é a origem processual do outro. Processual porque veio depois. Isto implica que o tempo perdido que deve ser recuperado é o tempo da ausência dos erros. Biblicamente, é o tempo anterior à queda de Adão, cujo estatuto foi redefinido a partir da vinda do Cristo. Assim, no calendário litúrgico, o início é o momento em que esse tempo foi renovado. O tempo do erro, ou o Tempo do Desvio, como escreveu Jacopo de Varazze, é o segundo na Legenda Áurea. Caberia uma questão: se foi redimido, por que ainda se fala dele? A resposta possível é: porque é digno de memória. Mesmo o desvio é exemplar, pois lembra os homens de sua origem pecadora e que é preciso evitar o pecado.

Antes como penitência, depois como confissão, nos séculos XII e XIII, principalmente, o pecado foi uma das principais categorias de entendimento e comportamento no Ocidente cristão. Uma tendência a considerar o livre-arbítrio tornou-se cada vez mais forte, tanto pela retomada de questões do direito romano quanto pela confissão auricular obrigatória (1215). Como instrumento de controle religioso, instaurou, pelo medo, a perseguição e interiorização do mal. Como instrumento de salvação, tornou-se indispensável pela busca de um sentido e para a salvação.

Consideramos, então, as hagiografias e os usos das vidas de santos como instrumentos e exemplos dessa busca. François Dosse caracterizou o 
santo das hagiografias como uma "epifania progressiva de um estado inicial de vocação ou de eleição". Para este autor, a vida do santo situa-se no tempo do que é constante, em que o fim repete o começo. ${ }^{62}$ Neste caso, mais que uma linearidade, o santo da hagiografia é personagem de uma circularidade, o que não exclui a trajetória biográfica. É certo que os dados biográficos na Legenda Áurea não são os elementos centrais dos textos. Mas, segundo Alain Boureau, Jacopo de Varazze relaciona as legendas com dados históricos, o que ancora as narrativas na verdade dos fatos humanos. ${ }^{63}$ Este aspecto é mais um dos recursos presentes nas hagiografias para aproximar o mundo que se conta no mundo em que se conta. Afinal, inserindo a vida do santo e seus milagres no curso cronológico do tempo daqueles que ouvem o relato, constrói-se um elo entre os tempos. Esses dados ora se referem ao ano de nascimento ou de morte, ora a um período governado por algum imperador ou, ainda, a um período em que o santo iniciou a penitência. ${ }^{64}$

Diferentemente dos capítulos santorais, ou seja, aqueles que remetem à festa específica de cada santo, nas legendas que narram o ciclo das vidas de Cristo (Advento, Natividade, Circuncisão, Epifania, Anunciação, Paixão, Ressurreição e Ascensão) e Maria (Purificação, Assunção e Natividade $)^{65}$ há um maior número de dados biográficos. É importante ressaltar que em todos os casos não é o dado biográfico o mais relevante, e, sim, o fato de sua inserção cronológica (no tempo do mundo em que se conta) atestar sua condição de verdade e legitimar, por uma razão ontológica, a lição que se deve extrair das legendas.

É por isso também que as legendas são imbricadas de temas como relatos fundadores (por exemplo, a de São Marcel), milagres de cura - pois fundamentam na maioria das vezes a crença -, defesa e punitivos, além, claro, da predominância do martírio. Segundo Hilário Franco Júnior, o belicismo e o contratualismo são os traços mais aparentes na Legenda Áurea ${ }^{66}$ Por belicismo o autor entende a significação das lutas constantes entre o Bem e o Mal, nas quais os santos eram os soldados do Bem. O contratua-

\footnotetext{
62 DOSSE, F. Le Pari Biographique: Écrire une vie. Paris: La Découverte, 2005. p. 150.

63 BOUREAU, A. La Légende Dorée: Le systhème narratif de Jacques de Voragine... Op. cit., p. 105.

64 Santo Amando, p. 263; São Bento, p. 306; Santa Maria Egipciaca, p. 352 -respectivamente. 65 Definidas por Alain Boureau como capítulos litúrgicos. Op. cit., p. 45.

66 FRANCO JÚNIOR, H. A outra face dos Santos: os milagres punitivos na Legenda Áurea. In: . A Eva barbada: ensaios de mitologia medieval. São Paulo: EDUSP, 1996. p. 221-229.
} 
lismo era a expressão de que todos os elementos da natureza, sobretudo o homem, participavam daquelas lutas. Mais ainda, já que uma neutralidade ética era impossível, os homens sempre estavam de um lado ou de outro. Assim, o papel dos santos também era "conquistar novos adeptos para a causa de Deus". Os milagres punitivos na Legenda Áurea advêm de uma noção corrente de santidade, a saber, de que "ser santo é punir alguns para recolocar outros no caminho correto" ${ }^{67}$ A morte (tanto o martírio santo quanto daquele que desafia o santo) é um elemento constante no texto de Jacopo. Sempre implica a conversão, o aumento da devoção ao santo e, consequentemente, a Deus. É comum na Legenda Áurea o santo que morre para provar que estava a serviço de Deus, assim como teria feito Jesus Cristo.

A ideia que o homem inevitavelmente se posiciona do lado do bem ou do mal está relacionada com o efeito de verdade que se intenta produzir nas hagiografias em geral, e na Legenda Áurea em específico, ou seja, a conversão. A partir disso, infere-se que os não santos tendiam para o lado da idolatria, do desregramento e da não observância das questões penitenciais. Daí a necessidade de intervenção dos "escravos de Deus" e suas punições exemplares não apenas com o objetivo de angariar novos cordeiros, mas também como elementos que vulgarizavam um sistema teológico amplo, do qual esses pecadores não participavam diretamente.

\section{Considerações finais}

Diante do que foi apresentado, analisado e discutido, podemos afirmar que as Hagiografias não são somente importantes documentos que ajudam a pensar a sociedade na Idade Média, como também contribuem para um enriquecimento das discussões sobre as reflexões sobre a narração do tempo, a história. Como fonte, a Legenda Áurea ajuda a pensar a questão da definição das fronteiras entre história e literatura na Idade Média. Como objeto de estudo, as vidas dos santos fornecem elementos para se pensar as tensões entre crenças, representações teológicas e suas formas de divulgação.

67 Ibidem, p. 222. 
Neste sentido, a hagiografia é uma ferramenta importante para se pensar na constituição de um regime de historicidade. Principalmente se o historiador intentar definir e (re)constituir o que foi o possível regime de historicidade cristão, entendido nos termos de François Hartog. A disposição temporal no texto hagiográfico evidencia não somente os recursos retóricos para se pensar o encadeamento entre passado, presente e futuro, como também as formas de transmissão de verdades, valores e crenças a partir da relação entre o mundo que se conta e o mundo em que se conta.

Os recursos retóricos mais comuns encontrados na Legenda Áurea são as tentativas de aproximação entre o maravilhoso e o cotidiano, ou seja, o aspecto milagroso e seus efeitos ou condições ontológicas. As analogias e as referências feitas ao tempo cronológico dão às hagiografias condições de produção do efeito de verdade desejado, ou seja, a propagação da crença cristã. A conversão pela palavra e pelo gesto, a nomeação do outro, a erradicação do paganismo, o martírio e o combate às heresias fazem dos santos verdadeiros instrumentos litúrgicos no texto e fundamentam as expectativas de salvação dos fiéis.

As hagiografias devem ser estudadas a partir de uma compreensão do sistema de valores que extrapola a interpretação interna dos textos. A função do texto hagiográfico é ampla e compreende um esforço de tradução e vulgarização da doutrina inserida na narrativa. Acreditamos que, para a Legenda Áurea, um dos aspectos externos mais importantes a serem considerados é a questão da confissão, que, por sua vez, está diretamente relacionada com as compreensões sobre o livre-arbítrio naquela sociedade. Desta forma, o conceito de livre-arbítrio revela uma autonomia que fornece dois finais: o do bem e o do mal. Neste sentido, o indivíduo pensado teologicamente é um indivíduo que está ciente das consequências de seus atos considerados negativos, ou seja, o pecado e o desregramento.

Recebido em janeiro de 2013.

Aprovado em maio de 2013. 